DOI: 10.20472/IAC.2019.045.025

\author{
LUCIA MUNONGI \\ University of Johannesburg, South Africa \\ JACE PILLAY \\ University of Johannesburg, South Africa
}

\title{
CHILDREN'S RESPONSIBILITIES IN THE ERA OF CHILDREN'S RIGHTS: IMPLICATIONS FOR PRACTICE
}

\begin{abstract}
:
Children's rights are unconditional entitlements that protect children from abuse. In South Africa, great strides have been made to advance children's rights through the Constitution and several other instruments on children's rights. A unique addition to the list of children's rights instruments was the creation of the Bill of Responsibilities for the Youth of South Africa. This Bill is meant to act as a flipside of the Children's Bill of Rights as it provides the responsivities that correspond to the rights that children have. This is an aspect that is not explicitly present in the Convention on the Rights of the Child as it only presents the responsibilities that the state and adults have towards fulfilling children's rights. The responsibilities are defined as those obligations that children have towards promoting the rights of other as well as achieving their own goals. The aim is to teach children about the link between rights and responsibilities and to inculcate in them the notion that rights with responsibilities can promote peaceful coexistence in society. This study explored the extent to which Grade 9 learners in two public schools in Johannesburg, South Africa, were practicing the responsibilities that come with their rights as given in the Bill of Responsibilities. Using a qualitative approach, data was collected through five learner focus groups (each group consisting of three boys and three girls), individual interviews with six learners (three boys and three girls) and individual interviews with five teachers (two males and three females. Content analysis was used to analyse data and the findings showed that in most cases learners were not practicing their responsibilities as given in the Bill of Responsibilities for the Youth of South Africa. Based on the findings, we recommend the need to teach children the link between rights and responsibilities.
\end{abstract}

\section{Keywords:}

Bill of Responsibilities, Bill of Rights, children, children's rights, children's responsibilities. 